\title{
Au-Pd Bimetallic Nanoparticles Immobilised on Titanate Nanotubes: A Highly Active Catalyst for Selective Oxidation
}

\author{
Motaz Khawaji $^{[a]}$, David Chadwick ${ }^{[]^{[}{ }^{\star}}$
}

In this work, a highly active Au-Pd/Ti-NT catalyst has been produced using colloidal synthesis and immobilisation on essentially sodium-free Ti-NTs. The new catalyst has markedly superior catalytic activity (TOF $=>19,000 \mathrm{hr}^{-1}$ ) for the selective oxidation of benzyl alcohol compared to similar catalysts reported in literature, and to Au-Pd catalysts supported on TiNTs prepared by adsorption, as well as conventional $\mathrm{Au}-\mathrm{Pd} / \mathrm{TiO}_{2}$ prepared by impregnation. The superior catalytic activity of the catalyst is shown to be due to the high metal dispersion on the external surfaces of Ti-NTs, the narrow particle size distribution, and the consistent formation of Au-Pd mixed alloy nanoparticles in close to a 1:1 wt. ratio. In repeated use the Au-Pd/Ti-NT catalyst showed only a modest fall in activity which is shown by FT-IR to be associated mainly with the irreversible adsorption of benzoic acid and benzyl benzoate by the catalyst.

\section{Introduction}

For a long time, gold was considered to be chemically inert and inactive. Haruta ${ }^{[1]}$ and Hutchings ${ }^{[2]}$ were the first to show independently the remarkable catalytic activity of gold nanoparticles (NPs). These landmark studies ushered a new age of gold catalysis. In subsequent studies, gold was found to be active for a range of reactions including the epoxidation of alkenes $^{[3]}$, selective oxidation of alcohols and carbohydrates ${ }^{[4]}$, activation of $\mathrm{C}-\mathrm{H}$ bonds ${ }^{[5]}$, and the direct synthesis of hydrogen peroxide under mild conditions ${ }^{[6]}$

It is well-known that the catalytic activity of gold is enhanced severalfold by alloying gold with palladium ${ }^{[7]}$. In the selective oxidation of alcohols to aldehydes, for instance, alloying $\mathrm{Au}$ with $\mathrm{Pd}$ can result in up to twenty-five-fold enhancement in the activity while retaining the selectivity ${ }^{[8]}$. The synergy between $\mathrm{Au}$ and $\mathrm{Pd}$ has been attributed to the ability of $\mathrm{Au}$ atoms to draw electron density away from $\mathrm{Pd}$ atoms [8]. Recently, Carter et al. reported that the introduction of $\mathrm{Pd}$ to $\mathrm{Au}$ enhances the catalytic activity in selective oxidation (of benzyl alcohol) while it was found to be detrimental to the activity in water-gas shift (WGS) reaction, CO oxidation, and formic acid decomposition ${ }^{[9]}$.

The catalytic activity of gold and gold-palladium catalysts is highly dependent on the metal dispersion, particle size, extent of alloying, and nature of the support. Titania has been extensively and successfully used a support material for $\mathrm{Au}$ and $\mathrm{Au}-\mathrm{Pd}$ catalysts. Indeed, several oxidation reactions have been shown to be active and selective with $\mathrm{Au}$ and $\mathrm{Au}-\mathrm{Pd}$ NPs supported on titania ${ }^{[3,10]}$. Titanate nanotubes possess several advantages over conventional titania. For instance, titania (Aeroxide® P25) has a surface area of $\sim 50 \mathrm{~m}^{2} / \mathrm{g}$ and surface hydroxyl group

[a] M. Khawaji, Prof. D. Chadwick

Department of Chemical Engineering Imperial College London

South Kensington, London, SW7 2AZ (UK)

E-mail: d.chadwick@imperial.ac.uk density $\sim 4.8-\mathrm{OH} / \mathrm{nm}^{2}{ }^{[11]}$, whereas Ti-NTs possess a surface area $\sim 250 \mathrm{~m}^{2} / \mathrm{g}$ on average and surface hydroxyl density $\sim 5.8$ $-\mathrm{OH} / \mathrm{nm}^{2}{ }^{212]}$. In general, the metal dispersion increases as the surface area and functionalities of the support increase ${ }^{[13]}$ Consequently, the combination of physiochemical properties possessed by titanate nanotubes (Ti-NTs) such as the open mesoporous structures, high specific surface area, high ionexchange capacity for various metals, and the good stability at moderately elevated temperatures ${ }^{[14]}$, a single nanotube is typically 50-200 nm in length and has an internal diameter ca. 3$8 \mathrm{~nm}$, and an outer diameter ca. 8-15 nm [15], making Ti-NTs a very attractive support material for highly dispersed Au and Au$\mathrm{Pd}$

In this work, we have attempted to leverage the high surface area and high population of surface $-\mathrm{OH}$ groups in TiNTs, and use them as anchoring sites for Au-Pd NPs. As we will show, this strategy proved to be successful and resulted in the creation of a highly active and stable selective oxidation catalyst.

The application of Au-Pd/Ti-NT in the direct synthesis of hydrogen peroxide from a mixture of molecular oxygen and hydrogen ${ }^{[16]}$, and the selective oxidation of salicylic alcohol ${ }^{[17]}$ has been reported previously. In these earlier studies, the Au$\mathrm{Pd} / \mathrm{Ti}-\mathrm{NT}$ catalysts were prepared by adsorption of the metal precursors on to the surface of Ti-NTs, followed by reduction with molecular hydrogen. These Au-Pd/Ti-NT catalysts were shown to have markedly higher activities in comparison with the equivalent catalysts supported on conventional metal oxide supports $\left(\mathrm{SiO}_{2}, \mathrm{Al}_{2} \mathrm{O}_{3}\right.$ and $\left.\mathrm{TiO}_{2}\right)$. Subsequently, the application $\mathrm{Au}-\mathrm{Pd} / \mathrm{Ti}-\mathrm{NT}$ in the liquid-phase selective oxidation of various alcohols has been investigated ${ }^{[18]}$, where Au-Pd/Ti-NT were prepared by adsorption on to $\mathrm{Na}-\mathrm{Ti}-\mathrm{NT}$ and again found to be more active than conventional $\mathrm{Au}-\mathrm{Pd} / \mathrm{TiO}_{2}$.

Titanate nanotubes can be synthesised by alkaline hydrothermal treatment as first described by Kasuga et al. ${ }^{[19}$ The efficient preparation of Au-Pd/Ti-NT by the adsorption method depends on the amount of sodium present in the titanate nanotubes, the type of metal precursors used and their concentration, as well as the $\mathrm{pH}$ of the solution since both adsorption and exchange processes take place. As a consequence, it is difficult to control the residual sodium content in the final catalyst, the metal dispersion, and the degree of alloy formation reproducibly. Therefore, an alternative preparation method of Au-Pd bimetallic catalysts that does not depend on the starting sodium content and gives a greater degree of alloy formation is highly desirable, and would lead to a more reproducible catalyst system.

Sol-immobilisation offers a major advantage over conventional preparation methods in that it allows for controlling the metal particle size irrespective of the support materia|l[20] and has been shown to give active Au-Pd catalysts on conventional oxide supports ${ }^{[21]}$, and carbon ${ }^{[22]}$. In the present work, we show that a highly active, stable, and reproducible selective oxidation catalyst based on the use of essentially sodium-free Ti-NTs as support, can be prepared by colloidal synthesis of Au-Pd NPs, their immobilisation on the external surface of the Ti-NTs, and the partial removal of the stabilizing agent by aqueous reflux. The catalytic performance has been demonstrated by the study of solvent-less selective oxidation of benzyl alcohol to benzaldehyde which is widely used as a model selective oxidation reaction for the study of supported Au-Pd catalysts ${ }^{[8,}$ 
23]. For comparison purposes the catalytic performance of Au$\mathrm{Pd} / \mathrm{Ti}-\mathrm{NT}$ prepared by adsorption, and $\mathrm{Au}-\mathrm{Pd} / \mathrm{TiO}_{2}$ prepared by conventional impregnation has also been examined. The new $\mathrm{Au}-\mathrm{Pd} / \mathrm{Ti}-\mathrm{NT}$ catalyst exhibits superior catalytic activity to similar $\mathrm{Au}-\mathrm{Pd}$ catalysts reported recently in literature, Au-Pd/Ti-NT catalysts prepared by adsorption, and conventional $\mathrm{Au}-\mathrm{Pd} / \mathrm{TiO}$ prepared by impregnation. Furthermore, it is shown that the high catalytic activity of the new catalyst compared to other titania or Ti-NT based catalysts is due to a unique combination of properties: viz the regular, small Au-Pd particle size, the near complete alloying of $\mathrm{Au}$ and $\mathrm{Pd}$ in each individual NP, and the high concentration of evenly distributed Au-Pd NPs on the external surfaces of Ti-NTs giving good accessibility of the reactants to the active catalytic centres.

The dependence on activity and selectivity on reaction conditions has been explored, and the catalyst deactivation and reuse has been investigated. In particular, the deactivation by adsorption of benzoic acid related species has been confirmed by TGA analysis and FT-infra-red spectroscopy of the recovered catalysts.

\section{Results and Discussion}

The Ti-NT were prepared by alkaline hydrothermal synthesis ${ }^{[18]}$. Two types of Ti-NT were used as catalyst support: one set in which some residual $\mathrm{Na}$ remained and was denoted as Ti-NT-1, and a second set which was subjected to further acid treatment to achieve an external surface containing minimum sodium, and denoted as Ti-NT-2. An $\mathrm{Au}-\mathrm{Pd} / \mathrm{TiO}_{2}$ catalyst was prepared for comparison by impregnation using P25 $\mathrm{TiO}_{2}$. Au-Pd/Ti-NT catalysts were characterised by XRD, HRTEM, XPS, $\mathrm{N}_{2}$ adsorption-desorption measurements, and analysed for metal content by ICP. The catalysts prepared by sol-immobilisation and absorption were further characterised by HAADF-STEM. The characterisation of the different catalysts prepared in this study is presented in the section below.

\section{Catalyst characterisation}

The formation of Ti-NTs by hydrothermal synthesis was confirmed by XRD, nitrogen adsorption-desorption measurements, and HRTEM. The XRD patterns for Ti-NTs and the starting material $\left(\mathrm{TiO}_{2}\right.$, anatase) are shown in the Supporting Information, Figure S1. The broad peak appearing at ca. $10.2^{\circ}$ $2 \theta$ in the XRD pattern corresponds to reflection from the $(200)$ plane, and is characteristic of titanate nanotubes. This peak is attributed to the interlayer spacing (d-spacing ca. $0.8-0.9 \mathrm{~nm})$ of the layered titanate phase ${ }^{[24],[25]}$. The peaks at $24.5^{\circ}, 28.6^{\circ}$ and $48.6^{\circ}$ are also indicative of tri-titanate $1 \mathrm{D}$ nanomaterials ${ }^{[26]}$. The weakening of the peak at $2 \theta=28.5^{\circ}$ and the broadening of the peak between at $10.2^{\circ} 2 \theta$ in Ti-NT-2 is due to the removal of $\mathrm{Na}$ and complete proton exchange $\mathrm{e}^{[26]}$. The surface areas, pore diameters, and pore volumes are given in Table 1 and are typical of Ti-NTs. The formation of Ti-NTs was also confirmed by TEM (Figures S2), where the multi-walled tubular structure of the synthesised Ti-NTs is clearly seen.

The Au-Pd sol was generated as described in the experimental section. Due to the presence of hydroxyl groups on the surface of Ti-NTs, the surface of Ti-NTs can be either positively or negatively charged depending on the $\mathrm{pH}$ of the dispersion medium. Zeta potential measurements for the assynthesised "sodium-free" Ti-NT-2 revealed that these Ti-NTs have a point of zero charge (PZC) of $\sim 5.2$ (Figure S3). PVAderived gold sols are negatively charged over a large range of $\mathrm{pH}$ values ${ }^{[27]}$. Hence, Ti-NT-2 were acidified to a $\mathrm{pH}$ value lower than the measured PZC. Upon the addition of Ti-NT-2, the negatively charged Au-Pd-PVA sol was readily adsorbed by the positively charged Ti-NT-2 surface.

In colloidal synthesis of metal NPs, the presence of the stabilising agent (PVA) in the final catalyst could be both advantageous and harmful. While it provides additional stability to the catalyst and prevents sintering and coalescence of the metal NPs, it can also shield the active catalytic centres and become detrimental to the catalytic activity ${ }^{[28]}$. Hutchings and coworkers have developed a technique for the facile removal of the stabilising agent by refluxing supported sol-derived $\mathrm{Au}-\mathrm{Pd} \mathrm{NPs}$ in hot water ${ }^{[29]}$. We applied the same technique to $\mathrm{Au}-\mathrm{Pd} / \mathrm{Ti}-\mathrm{NT}^{\mathrm{SI}}$ to give catalysts designated as Au-Pd/Ti-NTSI-R. As expected, the application of this technique led to some minor leaching of $\mathrm{Au}$ and Pd from the catalyst (see Table 1). Nevertheless, the treatment proved to be beneficial as it enhanced the surface exposure of Au-Pd NPs and improved the catalytic performance of $\mathrm{Au}-\mathrm{Pd} / \mathrm{Ti}-\mathrm{NT} \mathrm{T}^{\mathrm{SI}}$ as shown below.

The catalysts prepared in this study have a nominal metal loading of 2 wt.\% with a Au:Pd weight ratio equal to 1.0 corresponding to a Au:Pd atomic ratio $=1: 1.86$. Au-Pd/Ti-NT catalysts prepared by adsorption and $\mathrm{Au}-\mathrm{Pd} / \mathrm{TiO}_{2}$ catalysts prepared by dry impregnation, were treated with molecular hydrogen at a relatively moderate temperature of $200^{\circ} \mathrm{C}$ to avoid sintering of Au-Pd NPs, and damage to the structure of Ti-NTs. Previously it was shown that reduction of the metal precursors under these conditions is sufficient and produces active catalysts ${ }^{[16],[17]}$. The actual metal loadings of the reduced catalysts were determined by ICP-AES analysis (Table 1), and were found to be close to the nominal loading. Characterisation of $\mathrm{Au}-\mathrm{Pd}$ /Ti-NT by $\mathrm{N}_{2}$ adsorption-desorption measurements showed that no major changes in the textual properties of $\mathrm{Ti}$ NTs occur due to metal deposition (Table 1).

The catalysts were also analysed by XRD shown in Figure 1. Catalysts Au-Pd/Ti-NT ${ }^{\mathrm{ADS}}$ and $\mathrm{Au}-\mathrm{Pd} / \mathrm{TiO}_{2}{ }^{\mathrm{DI}}$ displayed relatively sharp peaks at $38.2^{\circ}$ corresponding to the pure gold

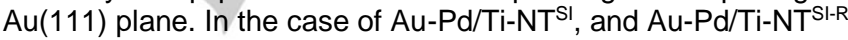
the peaks were slightly shifted with respect to $\mathrm{Au}(111)$ to $39.17^{\circ}$. This shift is due to the change in the lattice constant, and is indicative of the formation of a Au-Pd alloy phase ${ }^{[30]}$. No other clear diffraction peaks corresponding to $\mathrm{Au}$ or $\mathrm{Pd}$ diffraction planes were observed owing to the low metal concentration and relatively small particle size of the metal NPs.

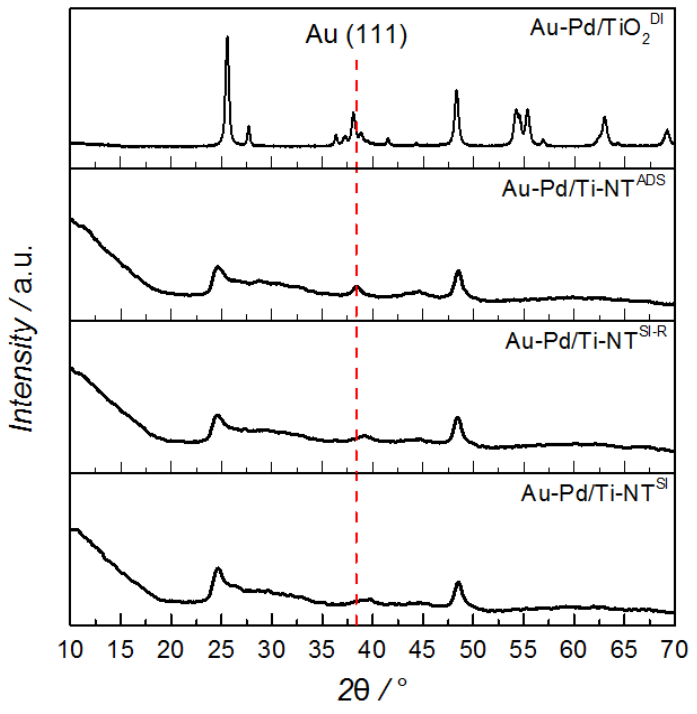

Figure 1. X-ray diffraction patterns for the Au-Pd/Ti-NT catalysts prepared. 
Table 1. Metal composition and textural properties of Ti-NTs and the Au-Pd catalysts

\begin{tabular}{|c|c|c|c|c|c|c|c|c|}
\hline & $\begin{array}{l}\mathrm{Pd}^{[a],[b]} \\
{[w t . \%]}\end{array}$ & $\begin{array}{l}\mathrm{Au}^{[\mathrm{a}],[\mathrm{b}]} \\
{[\mathrm{wt} . \%]}\end{array}$ & $\begin{array}{l}\mathrm{Na}^{[\mathrm{a}]} \\
{[\mathrm{wt} . \%]}\end{array}$ & Pd:Au weight ratio & $\mathrm{Pd}: \mathrm{Au}$ atomic ratio & $\begin{array}{l}\mathrm{S}_{B E T}{ }^{[c]} \\
{\left[\mathrm{m}^{2} / \mathrm{g}\right]}\end{array}$ & $\begin{array}{l}\text { Pore volume }{ }^{[\mathrm{c}]} \\
\qquad\left[\mathrm{cm}^{3} / \mathrm{g}\right]\end{array}$ & $\begin{array}{c}\text { Pore diameter }{ }^{[\mathrm{c}]} \\
{[\mathrm{nm}]}\end{array}$ \\
\hline Ti-NT-1 (Na) & - & - & 5.27 & - & - & 174 & 0.36 & 7.31 \\
\hline Ti-NT-2 (minimum Na) & - & - & 0.02 & - & - & 236 & 0.51 & 7.68 \\
\hline $\mathrm{Au}-\mathrm{Pd} / \mathrm{Ti}-\mathrm{NT}^{\mathrm{SI}}$ & 0.81 & 0.73 & 0.02 & 1.11 & 2.05 & 217 & 0.52 & 8.21 \\
\hline $\mathrm{Au}-\mathrm{Pd} / \mathrm{Ti}-\mathrm{NT} \mathrm{T}^{\mathrm{SI}-\mathrm{R}}$ & 0.77 & 0.70 & $-[d]$ & 1.10 & 2.04 & 217 & 0.52 & 8.21 \\
\hline Au-Pd/Ti-NT ADS & 0.88 & 0.64 & 2.37 & 1.38 & 2.54 & 206 & 0.45 & 6.93 \\
\hline $\mathrm{Au}-\mathrm{Pd} / \mathrm{TiO}_{2}{ }^{\mathrm{DI}}$ & 1.10 & 0.81 & $-[d]$ & 1.36 & 2.51 & 54 & 0.28 & 18.30 \\
\hline
\end{tabular}

[a] Weight percentage per gram of sample, obtained by ICP-AES analysis.

[b] Nominal loading for $\mathrm{Au}=1 \mathrm{wt} . \%$ and $\mathrm{Pd}=1 \mathrm{wt} . \%$ in all samples.

[c] Determined by nitrogen adsorption-desorption measurements.

[d] Undetected by ICP
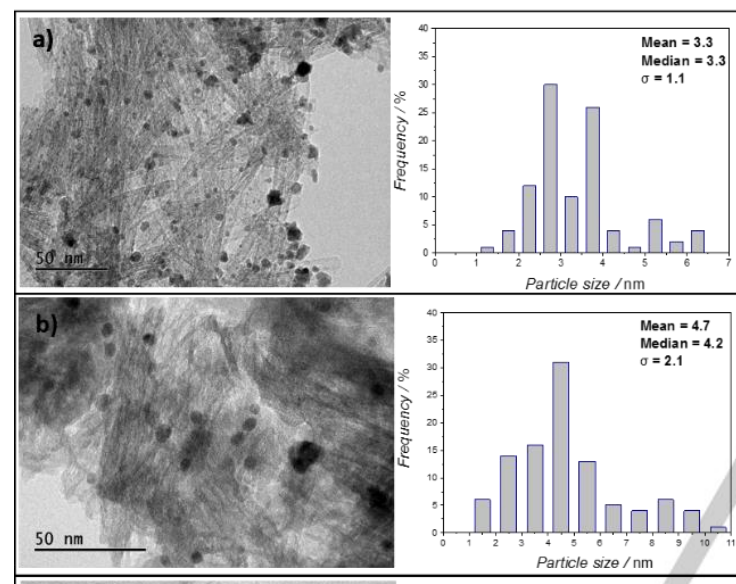

c)

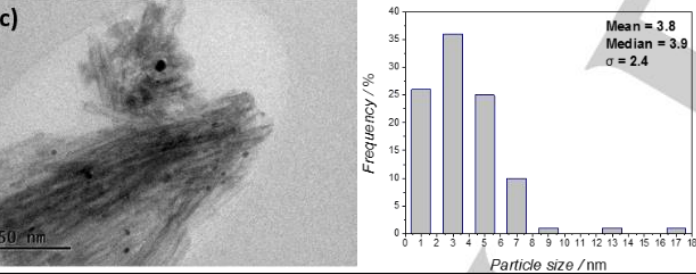

Figure 2. HRTEM images and the corresponding particle size distribution for a) Au-Pd/Ti-NT ${ }^{S I}$, b) Au-Pd/Ti-NT ${ }^{\mathrm{SI}-\mathrm{R}}$, c) Au-Pd/Ti-NT ${ }^{\mathrm{ADS}}$

HRTEM analysis for the Au-Pd/Ti-NT catalysts are shown in Figure 2. These HRTEM images revealed information about the structure and morphology of the catalysts, as well as the particle size distribution (PSD) of Au-Pd NPs on the surface of Ti-NTs. The catalyst sample prepared by sol-immobilisation (Figure 2a) exhibited the narrowest particle size distribution and smallest mean particle size. The refluxed catalyst (Figure $2 \mathrm{~b}$ ) exhibited a slightly larger mean particle size, which is in agreement with previous studies concerning the effect of reflux ${ }^{[29],[31]}$. Catalysts prepared by adsorption (Figure 2c) exhibited a small mean particle size, and a slightly wider PSD. Significantly, TEM images of Au-Pd/Ti-NTSI and Au-Pd/Ti-NTSI-R

(Figure 2a and $\mathrm{b}$ ) highlight an important and distinctive feature which is the noticeably high surface loading density. Although all catalysts have nearly the same overall metal loading, $\mathrm{Au}-\mathrm{Pd} / \mathrm{Ti}-$ $\mathrm{NT}^{\mathrm{SI}}$ and $\mathrm{Au}-\mathrm{Pd} / \mathrm{Ti}-\mathrm{NT} \mathrm{Tl}^{\mathrm{SI}}$ display the largest population of $\mathrm{Au}-\mathrm{Pd}$ NPs. Catalyst sample Au-Pd/Ti-NTSI-R was further characterised with STEM (Figure 3 ) in which the highly dispersed, regular nature of the Au-Pd NPs is clearly seen. In this work and in previous work ${ }^{[17]}$ it was observed that in the case of $\mathrm{Au}-\mathrm{Pd} / \mathrm{Ti}$ NTADS a significant number of NPs appear to have a rod-like shape and be elongated along the long axis of the Ti-NTs, and have a width equivalent to the inner diameter of a single nanotube (i.e. 3-8 nm). It was previously suggested that this is due to the constraint from the radial curvature of the NTs and the axial degree of freedom. However, it might imply that some of the NPs are confined inside the tubular structure of Ti-NTs. Furthermore, because of the layered structure of Ti-NTs, it is also possible for metal ions to occupy the interstitial cavities (typically $0.7-0.9 \mathrm{~nm}$ ) between the different layers that make up a single nanotube ${ }^{[14]}$. Hence, the extremely small nanoparticles $(<1.0 \mathrm{~nm})$ observed in Au-Pd/Ti-NTADS may well be located in the interstitial sites of Ti-NTs.

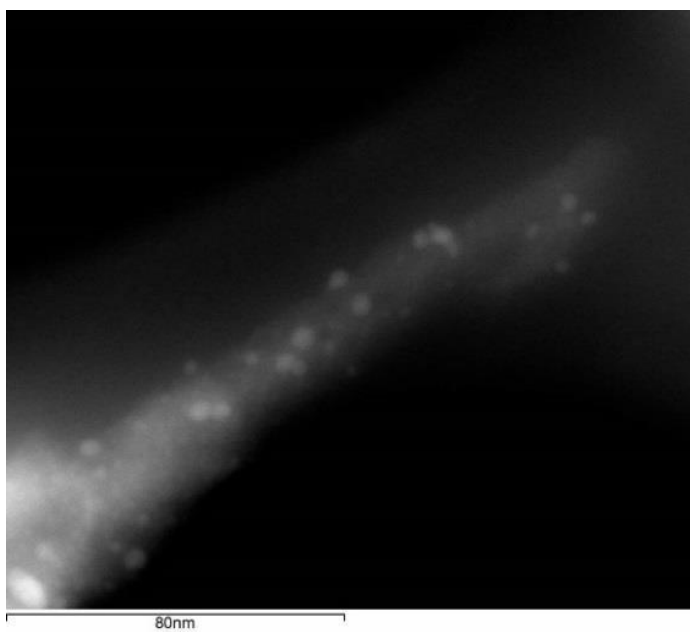

Figure 3. HAADF-STEM images for Au-Pd/Ti-NT Sl-R 
To investigate the surface chemistry and atomic composition of $\mathrm{Au}-\mathrm{Pd} / \mathrm{Ti}-\mathrm{NT}$, the catalysts were also characterised by XPS. The surface atomic concentrations are given in Table 3; measured peak area ratios are given in Table S1. It is striking that the catalyst prepared by sol-immobilisation (Au-Pd/Ti-NTSI) showed a markedly higher surface concentration than $\mathrm{Au}-\mathrm{Pd} / \mathrm{Ti}-\mathrm{NT}^{\mathrm{ADS}}$. Furthermore, Au-Pd/Ti-NTSI-R exhibited even higher $\mathrm{Au}$ and $\mathrm{Pd}$ surface concentrations than $\mathrm{Au}-\mathrm{Pd} / \mathrm{Ti}$ $\mathrm{NT}^{\mathrm{SI}}$, which is clear evidence that the refluxing technique does indeed improve the surface exposure of the Au-Pd NPs on the surface of Ti-NTs (Table 3 ). The combined Au-Pd surface concentration in $\mathrm{Au}-\mathrm{Pd} / \mathrm{Ti}-\mathrm{NT} \mathrm{T}^{\mathrm{SI}-\mathrm{R}}$ is 10 times that of $\mathrm{Pd} / \mathrm{Ti}-\mathrm{NT} \mathrm{T}^{\mathrm{ADS}}$. The low $\mathrm{Au}$ and $\mathrm{Pd}$ surface concentration observed in $\mathrm{Au}-\mathrm{Pd} / \mathrm{Ti}$ NTADS could be ascribed to the confinement of some small NPs $(<5 \mathrm{~nm})$ inside the tubular morphology of the titanate nanotubes. Because of the limited escape depth of electrons emitted in XPS and relatively thick walls of Ti-NTs (ca. 4-8 nm), Au-Pd NPs entrapped inside the nanotubes would not contribute significantly to the measured spectral intensity. The XPS analysis depth for $\mathrm{Au}(4 \mathrm{f})$ was recently reported to be between 5.4 and $5.8 \mathrm{~nm}$; for $\mathrm{Pd}(4 \mathrm{~d})$ XPS signal the analysis depth was found to be between 4.6-5.0 $\mathrm{nm}^{[32]}$. Interestingly, therefore, although Au-Pd/Ti-NTADS exhibited a small mean particle size $(3.8 \mathrm{~nm})$ and a reasonably high dispersion, it displayed relatively weak Au and Pd XPS intensities and low surface concentration, Table 3. This might be taken as confirming the hypothesis that in the case of $\mathrm{Au}-\mathrm{Pd} / \mathrm{Ti}-\mathrm{NT} \mathrm{TDS}^{\mathrm{ADS}}$ a significant fraction of the smallest Au-Pd NPs is located inside the pores and interstitial sites of TiNTs. On the other hand, Au-Pd NPs prepared by colloidal synthesis are essentially wrapped by the stabilising polymer and hence are more likely to be on the exterior surfaces of Ti-NTs due to the spatial constraint imposed by the size of the inner diameter of the nanotubes. It is also plausible that during the immobilisation of the Au-Pd sol the negatively charged acetate groups in the partially hydrolysed PVA chains adsorb strongly to the positively charged $\mathrm{Ti}_{-} \mathrm{HO}_{2}{ }^{+}$species on the external surface of Ti-NTs, and prevent the dispersion of the Au-Pd NPs inside the pores. Additionally, it is important to highlight that the atomic $\mathrm{Pd}: A u$ ratio in $\mathrm{Au}-\mathrm{Pd} / \mathrm{Ti}-\mathrm{NT} \mathrm{T}^{\mathrm{Sl}-\mathrm{R}}$ and $\mathrm{Au}-\mathrm{Pd} / \mathrm{Ti}-\mathrm{NT}^{\mathrm{Sl}}$ is very close to the actual ratio given in Table 1 , which is indicative of the homogenous distribution and alloying of both $\mathrm{Au}$ and $\mathrm{Pd}$ on the external surface of Ti-NTs.

Table 3. Surface concentration as determined by XPS

\begin{tabular}{|c|c|c|c|c|c|c|}
\hline \multirow[t]{2}{*}{ Catalyst } & \multicolumn{6}{|c|}{ Surface content [atomic\%] } \\
\hline & $\mathrm{Au}(4 \mathrm{f})$ & $\operatorname{Pd}(3 d)$ & $C(1 s)$ & $\mathrm{Ti}(2 \mathrm{p})$ & $O(1 s)$ & $\mathrm{Pd}: \mathrm{Au}$ \\
\hline $\mathrm{Au}-\mathrm{Pd} / \mathrm{Ti}-\mathrm{NT} \mathrm{T}^{\mathrm{SI}}$ & 1.0 & 2.0 & 12.0 & 23.7 & 60.8 & 1.98 \\
\hline $\mathrm{Au}-\mathrm{Pd} / \mathrm{Ti}-\mathrm{NT} \mathrm{T}^{\mathrm{SI}-\mathrm{R}}$ & 1.86 & 4.09 & 10.1 & 30.9 & 53.0 & 2.20 \\
\hline Au-Pd/Ti-NTADS & 0.22 & 0.39 & 5.9 & 31.5 & 62.0 & 1.77 \\
\hline
\end{tabular}

Catalyst sample Au-Pd/Ti-NTADS exhibited a clear Au(4f) peak at $~ 84 \mathrm{eV}$, Figure 4, which corresponds to the pure monometallic reduced phase of gold $\left(\mathrm{Au}^{0}\right)$. In comparison, $\mathrm{Au}-$ $\mathrm{Pd} / \mathrm{Ti}-\mathrm{NT} \mathrm{SI}^{\mathrm{SI}}, \mathrm{Au}-\mathrm{Pd} / \mathrm{Ti}-\mathrm{NT} \mathrm{T}^{\mathrm{SI}} \mathrm{R}$ exhibited peaks at slightly lower binding energies. This peak shift from $\sim 84.0 \mathrm{eV}$ to $\sim 83.5 \mathrm{eV}$ could be ascribed to the electronic modification of Au species by $\mathrm{Pd}$, and is indicative of a close interaction between the $\mathrm{Au}$ and $\mathrm{Pd}$ atoms, and the formation of Au-Pd alloys ${ }^{[9,33]}$. The small peaks $\left(\mathrm{Au}^{\delta+}\right)$ appearing at B.E. $85.4 \mathrm{eV}$ are likely due to the presence of some oxidised gold species arising from drying and transfer ${ }^{[9,}{ }^{34]}$. However, some have also attributed this peak $\left(\mathrm{Au}^{\delta+}\right)$ to the very small gold nanoparticles ${ }^{[9,34]}$. The XPS and XRD results are consistent, therefore, and confirm that the Au$\mathrm{Pd}$ NPs are present mostly as alloys in $\mathrm{Au}-\mathrm{Pd} / \mathrm{Ti}-\mathrm{NT}^{\mathrm{SI}}$ and $\mathrm{Au}-$ $\mathrm{Pd} / \mathrm{Ti}^{-N} \mathrm{NT}^{\mathrm{SI}-\mathrm{R}}$. No chloride was detected by XPS in any of the catalyst samples demonstrating the full reduction of the metal precursors and removal of chlorides. The corresponding $\mathrm{Pd}(3 \mathrm{~d})$ spectra are given in Supporting Information Figure S4. There is again evidence of surface oxidation during the drying and transfer. This is more apparent in Au-Pd/Ti-NTADS which is consistent with the presence of a significant fraction of unalloyed particles (see below).

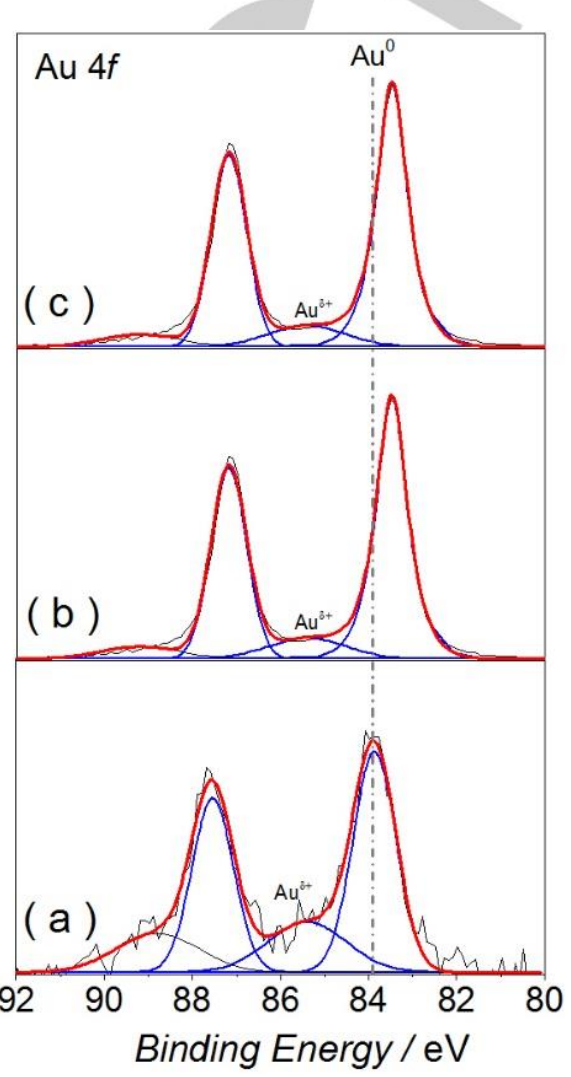

Figure 4. XPS spectra of $A u(4 f)$ in a) $A u-P d / T i-N T^{A D S}$, b) $A u-P d / T i-N T^{S I}$, and c) $\mathrm{Au}-\mathrm{Pd} / \mathrm{Ti}-\mathrm{NT}^{\mathrm{SI}-\mathrm{R}}$.

Au-Pd/Ti-NTSI-R catalyst was further analysed by STEMEDX, Figure 5. The elemental mapping of a single Au-Pd NP revealed that these particles are truly mixed random alloys of $\mathrm{Au}$ and $\mathrm{Pd}$. In order to determine the extent of alloying, $69 \mathrm{NPs}$ were randomly selected and analysed by STEM-EDX (Figure S5). Remarkably, the vast majority (83\%) of the analysed NPs were found to be mixed Au-Pd alloys with a $\mathrm{Au}: \mathrm{Pd}$ weight ratio equal to $1.0 \pm 0.2$. Therefore, the analysis carried out on Au$\mathrm{Pd} / \mathrm{Ti}_{-N T} \mathrm{NII}^{\mathrm{R}}$ using XRD, XPS and STEM-EDX establishes that the overwhelming majority of the NPs are undoubtedly mixed alloys of $\mathrm{Au}$ and $\mathrm{Pd}$, and by implication the same is true of $\mathrm{Au}$ $\mathrm{Pd} / \mathrm{Ti}-\mathrm{NTSl}$. The relatively low degree of alloying or lack of it in catalyst Au-Pd/Ti-NTADS was further confirmed by STEM-EDX. A few NPs were selected and analysed with STEM-EDX, and showed to be either monometallic in nature or poorly alloyed (Figure S6), which is in agreement with the XRD and XPS results. 


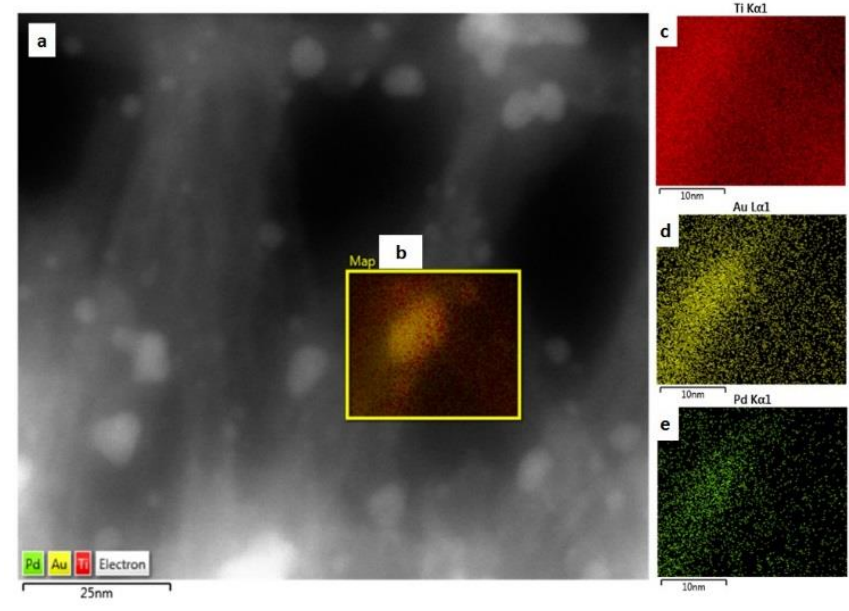

Figure 5. a) HAADF-STEM image for $\mathrm{Au}-\mathrm{Pd} / \mathrm{Ti}-\mathrm{NT} \mathrm{T}^{\mathrm{SI}-\mathrm{R}}$, b) reconstructed overlay image of the STEM-EDX elemental maps shown in c), d) and e).

\section{Catalytic activity}

The solvent-less selective oxidation of benzyl alcohol to benzaldehyde has traditionally been used as a model oxidation reaction for studying Au-Pd supported catalysts. While the primary product in the selective oxidation of benzyl alcohol is benzaldehyde, other products such as toluene, benzene, benzoic acid and benzyl benzoate can also be produced in often competing reaction pathways ${ }^{[35]}$. Consequently, the reaction is a good test of the selective oxidation performance of $\mathrm{Au}-\mathrm{Pd}$ supported catalysts.

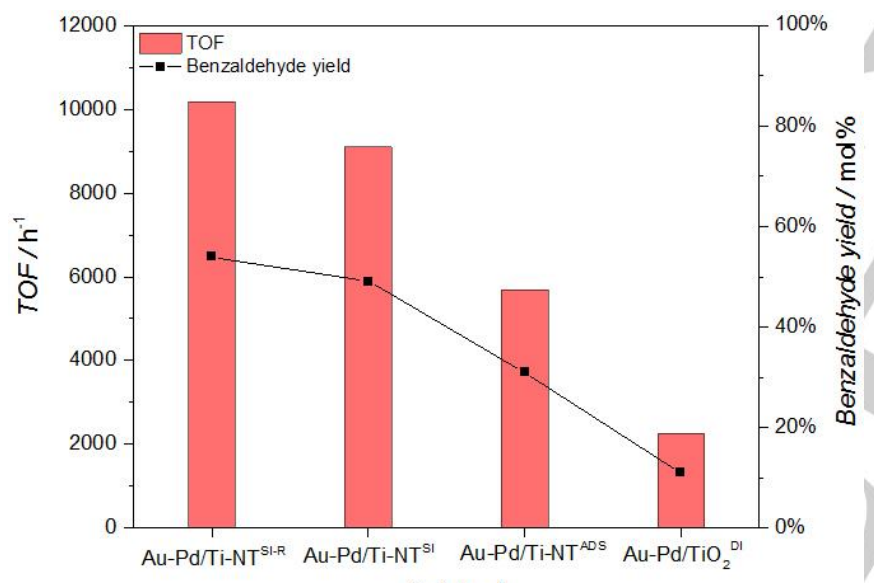

Catalyst

Figure 6. TOF $\left(\mathrm{h}^{-1}\right)$ and benzaldehyde yield obtained for the different Au$\mathrm{Pd} / \mathrm{Ti}-\mathrm{NT}$ catalysts. Reaction conditions: $\mathrm{T}=120^{\circ} \mathrm{C}, \mathrm{P}_{\mathrm{O} 2}=4 \mathrm{bar}$, stirring rate $=1,000 \mathrm{rpm}$, reaction time $=1$ hour, catalyst $=12 \mathrm{mg}$, benzyl alcohol $=2.5 \mathrm{~g}$.

All the catalysts were tested for benzyl alcohol selective oxidation under the same reaction conditions $\left(T=120^{\circ} \mathrm{C}, \mathrm{P}_{\mathrm{O} 2}=4\right.$ bar, stirring rate $=1,000 \mathrm{rpm}$, reaction time $=1 \mathrm{~h}$, catalyst weight $=12 \mathrm{mg}$ ). In a preliminary study, conversion was found to be independent of stirrer speed in the range 600-1000 rpm. A study of conversion versus catalyst weight at a constant reaction time of $1 \mathrm{~h}$ was essentially linear up to $12 \mathrm{mg}$ and overall was a good fit to a first order reaction, Figure S7 and Table S2, demonstrating, as the pressure of oxygen was maintained constant, that the reaction was kinetically controlled at these conditions. Conversion versus reaction time for $18 \mathrm{mg}$ of catalyst was a good fit to a first order reaction up $1 \mathrm{~h}$, but deviated thereafter, Figure S8, probably due to the onset of some deactivation as discussed below. From these initial investigations, $12 \mathrm{mg}$ of catalyst and a reaction time of $1 \mathrm{~h}$ were selected to compare catalyst performance free of the effects of any deactivation and in the kinetic regime, and minimise the effect of heat-up time which was about $8 \mathrm{~min}$.

The benzyl alcohol conversion and product selectivity for the different Au-Pd/Ti-NT catalysts are given in Table 4. Each reaction was repeated three times, and the average values were reported. In the absence of any catalyst, a small conversion (ca. $4.4 \mathrm{~mol} \%$ ) was obtained most probably due to the autoxidation of benzyl alcohol with molecular oxygen. The two catalyst samples prepared by sol-immobilisation (i.e. Au-Pd/Ti-NT'sl and $\mathrm{Au}-\mathrm{Pd} / \mathrm{Ti}-\mathrm{NT} \mathrm{T}^{\mathrm{SI}} \mathrm{R}$ ) were significantly more active and gave higher yields of benzaldehyde. In terms of turnover frequency (moles of benzyl alcohol converted per mole of metal), Au-Pd/Ti-NTSi-A displays nearly double the catalytic activity of Au-Pd/Ti-NTADS, and more than triple the activity of the $\mathrm{Au}-\mathrm{Pd} / \mathrm{TiO}_{2}{ }^{\mathrm{Dl}}$ reference catalyst. The high degree of Au-Pd alloy formation achieved in $\mathrm{Au}-\mathrm{Pd} / \mathrm{Ti}_{-N T^{\mathrm{SI}}}$ and Au-Pd/Ti-NTSI-R is a major factor in the superior activity of these catalysts. In addition, in Au-Pd/Ti-NTSI and $\mathrm{Au}-\mathrm{Pd} / \mathrm{Ti}-\mathrm{NT}^{\mathrm{SI}-\mathrm{R}}$ all the metal NPs were consistently in the range 1-10 nm in diameter and were alloyed, whereas Au-Pd/TiNTADS presents some larger particles. Only small metal NPs that are $\leq 10$ contribute significantly to the catalytic activity, whereas larger NPs $>10 \mathrm{~nm}$ are essentially catalytically inactive as reported by previous studies of alcohol oxidation [31, 36]. Furthermore, the high catalytic activity displayed by $\mathrm{Au}-\mathrm{Pd} / \mathrm{Ti}-$ $\mathrm{NT}^{\mathrm{SI}}$ and $\mathrm{Au}-\mathrm{Pd} / \mathrm{Ti}-\mathrm{NT} \mathrm{SI}^{\mathrm{S}} \mathrm{R}$ is also enhanced by the location of the $\mathrm{Au}-\mathrm{Pd}$ NPs on the external surface of the titanate nanotubes rather than in the inner pores or the inertial sites, which makes all the NPs accessible to the reactants. In sum, the superior catalytic activity of Au-Pd/Ti-NTSI-R in comparison to the other catalysts prepared in this study can be attributed to: 1) the narrow PSD and small mean particle size, 2) the consistent formation of mixed Au-Pd alloyed NPs, 3) the enhanced accessibility to the active metal sites by the reactants, and 4) the high surface concentration of $\mathrm{Au}$ and $\mathrm{Pd}$.

Although catalyst Au-Pd/Ti-NT ${ }^{\mathrm{SI}-\mathrm{R}}$ was reduced in-situ with $\mathrm{NaBH}_{4}$ at room temperature, as a check it was also further treated under the same reduction conditions used for the other catalysts, and then tested in the selective oxidation of benzyl alcohol. The performance of the so-treated Au-Pd/Ti-NTSI-R catalyst remained virtually unchanged, which confirms that the superior catalytic activity of $\mathrm{Au}-\mathrm{Pd} / \mathrm{Ti}-\mathrm{NT} \mathrm{T}^{\mathrm{S}}-\mathrm{R}$ is due to the distinct structural and morphological properties of the catalyst and not to the reduction conditions.

It is noteworthy to highlight that catalyst $\mathrm{Au}-\mathrm{Pd} / \mathrm{Ti}-\mathrm{NT} \mathrm{T}^{\mathrm{SI}} \mathrm{R}$ achieved a TOF comparable or higher than those reported for $\mathrm{Au}-\mathrm{Pd} / \mathrm{NaTi}-\mathrm{NT}^{[18]}\left(318 \mathrm{~h}^{-1}\right)$, Au-Pd-PVA/TiO ${ }_{2}^{[23]}\left(10,300 \mathrm{~h}^{-1}\right)$, and the recently reported $\mathrm{Au}-\mathrm{Pd}-\mathrm{GO} / \mathrm{TiO}_{2}$ composites ${ }^{[23]}\left(10,400 \mathrm{~h}^{-1}\right)$. Indeed, when Au-Pd/Ti-NT ${ }^{\mathrm{SI}-\mathrm{R}}$ was tested under exactly the same reaction conditions as used in the latter study ${ }^{[23]}$ (benzyl alcohol $=1.0 \mathrm{~g}$, catalyst $=10 \mathrm{mg}, \mathrm{T}=120^{\circ} \mathrm{C}, \mathrm{P}_{\mathrm{O} 2}=1$ bar, stirring rate $=1,000 \mathrm{rpm}$, reaction time $=0.5 \mathrm{~h}$ ), a TOF exceeding $14,000 \mathrm{~h}^{-1}$ was obtained, and under our standard conditions at $0.5 \mathrm{~h}$ reaction time the turnover frequency can exceed $19,000 \mathrm{~h}^{-1}$.

\section{Effect of reaction conditions}

Using the most active catalyst (Au-Pd/Ti-NT ${ }^{\mathrm{SI}-\mathrm{R}}$ ), the effect of varying the reaction conditions on the activity and selectivity for benzyl alcohol selective oxidation has been investigated. As noted above, benzaldehyde is formed by the sequential 
oxidative dehydrogenation of benzyl alcohol, while further oxidation produces benzoic acid. However, there are several other by-products from competing pathways which are sensitive to the reaction conditions. Benzyl ether is produced by the dehydration of benzyl alcohol, and benzyl benzoate is formed by either of two pathways: the esterification of benzoic acid by benzyl alcohol, or via hemi-acetal from benzaldehyde. Benzene is formed by the decarbonylation of benzaldehyde ${ }^{[37]}$. The origin

Table 4. Benzyl alcohol conversion and product selectivity for the different catalysts ${ }^{[a]}$

\begin{tabular}{|c|c|c|c|c|c|c|c|c|}
\hline \multirow[t]{2}{*}{ Catalyst } & \multirow{2}{*}{$\begin{array}{c}\text { Conversion } \\
\text { [\%] }\end{array}$} & \multirow{2}{*}{$\begin{array}{l}\text { TOF }^{[\mathrm{b}]} \\
{[1 / \mathrm{h}]}\end{array}$} & \multicolumn{6}{|c|}{ Product Selectivity [mol\%] } \\
\hline & & & Benzaldehyde & Toluene & Benzene & Benzyl ether & Benzoic acid & Benzyl benzoate \\
\hline Blank & 4.4 & - & 83.7 & 2.6 & 13.7 & 0 & 0 & 0 \\
\hline $\mathrm{Au}-\mathrm{Pd} / \mathrm{Ti}-\mathrm{NT} \mathrm{TI}^{\mathrm{SI}}$ & 61.6 & 9,096 & 79.5 & 12.8 & 2.4 & 1.9 & 1.3 & 2.2 \\
\hline $\mathrm{Au}-\mathrm{Pd} / \mathrm{Ti}-\mathrm{NT}^{\mathrm{ADS}}$ & 36.1 & 5,693 & 86.1 & 8.2 & 0.8 & 0.7 & 1.9 & 2.2 \\
\hline $\mathrm{Au}-\mathrm{Pd} / \mathrm{TiO}_{2}{ }^{\mathrm{II}}$ & 14.0 & 2,260 & 78.6 & 10.5 & 7.9 & 1.1 & 0.2 & 1.7 \\
\hline
\end{tabular}

[a] Reaction conditions: $\mathrm{T}=120^{\circ} \mathrm{C}, \mathrm{PO}_{2}=4 \mathrm{bar}$, stirring rate $=1,000 \mathrm{rpm}$, reaction time $=1$ hour, catalyst $=12 \mathrm{mg}$, benzyl alcohol $=2.5 \mathrm{~g}$

[b] Turnover frequency is expressed per total metal loading as determined by ICP-AES.

of toluene has been debatable for a long time ${ }^{[38]}$, some suggested that it is produced as a result of the hydrogenolysis of benzyl alcohol[39]. However, in light of more recent studies, disproportionation of benzyl alcohol appears to be the most likely source of toluene ${ }^{[38 b]}$.

The catalytic activity of Au-Pd/Ti-NTSI-R as a function of reaction time is shown in Figure $7 \mathrm{a}$ and the corresponding product selectivities are given in Table 5 . We found that Au$\mathrm{Pd} / \mathrm{Ti}^{-N T^{\mathrm{SI}}-\mathrm{R}}$ was remarkably active after $15 \mathrm{~min}$, exhibiting a
TOF > 19,000 $\mathrm{h}^{-1}$ and benzyl alcohol conversion ca. 33\%. The catalyst was marginally more selective to benzaldehyde at short reaction times as expected, displaying benzaldehyde selectivity ca. $83.2 \mathrm{~mol} \%$ at 30 minutes. As the reaction time is increased, higher benzyl alcohol conversion and benzaldehyde yield are obtained, while reaction selectivity towards benzaldehyde decreased to 79.7 mol\% at 120 minutes and remained virtually constant thereafter.
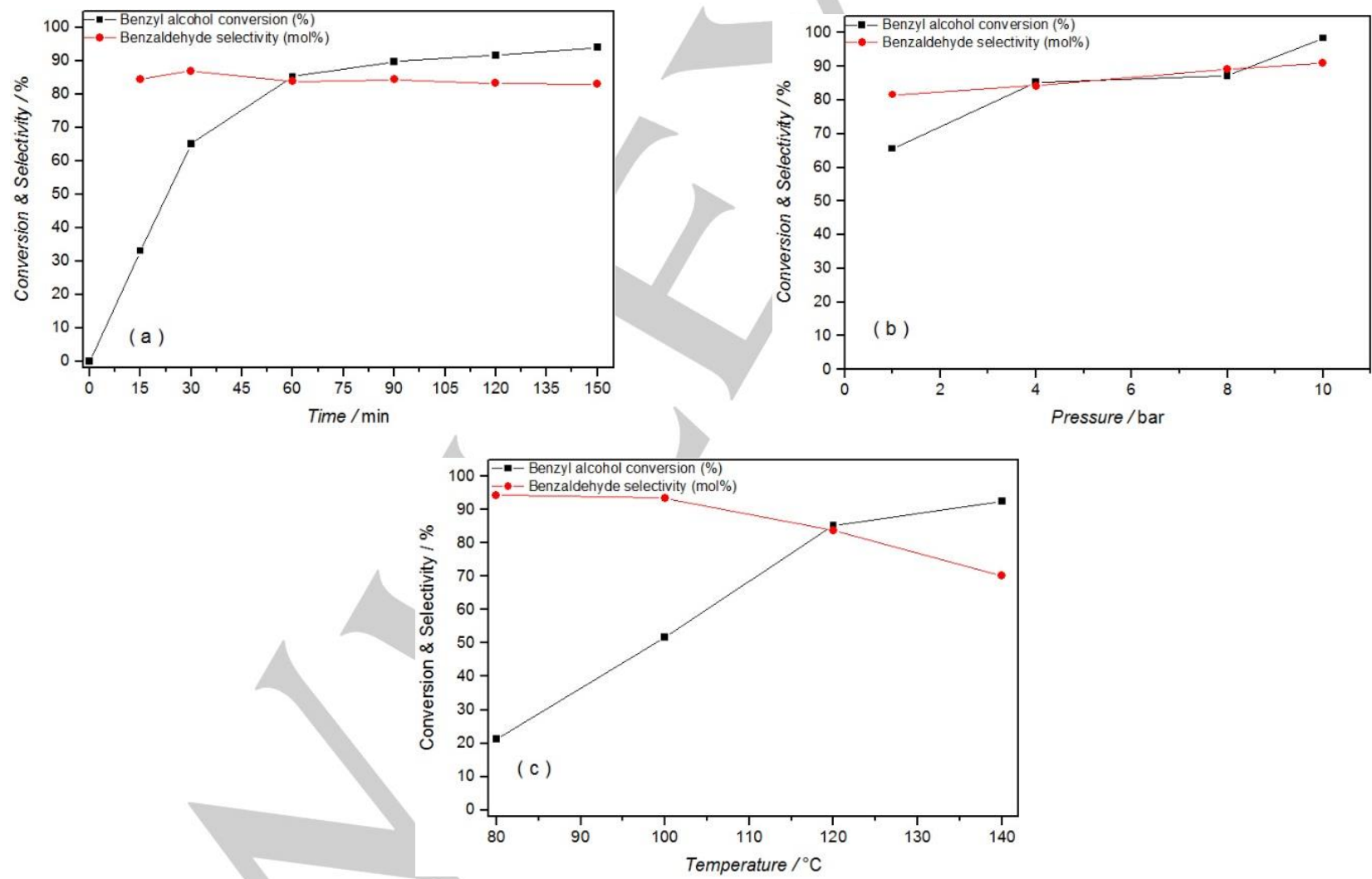

Figure 7. Effect of (a) time, (b) $\mathrm{O}_{2}$ partial pressure, and (c) temperature on benzyl alcohol conversion, and benzaldehyde selectivity for Au-Pd/Ti-NTSI-R. 
Table 5. Benzyl alcohol conversion and product selectivity at different reaction times for Au-Pd/Ti-NTSI-R [a]

\begin{tabular}{|c|c|c|c|c|c|c|c|}
\hline \multirow{2}{*}{$\begin{array}{l}\text { Time } \\
\text { [min] }\end{array}$} & \multirow{2}{*}{$\begin{array}{c}\text { Conversion } \\
\text { [\%] }\end{array}$} & \multicolumn{6}{|c|}{ Product Selectivity [mol\%] } \\
\hline & & Benzaldehyde & Toluene & Benzene & Benzyl ether & Benzoic acid & Benzyl benzoate \\
\hline 15 & 33.1 & 80.9 & 9.6 & 1.2 & 2.5 & 2.1 & 3.7 \\
\hline 30 & 65.2 & 83.2 & 9.8 & 1.5 & 1.8 & 1.1 & 2.6 \\
\hline 60 & 85.3 & 80.2 & 11.1 & 2.3 & 2.3 & 1.2 & 2.5 \\
\hline 90 & 89.8 & 80.7 & 10.6 & 2.1 & 2.1 & 1.4 & 3.1 \\
\hline 120 & 91.7 & 79.7 & 11.1 & 2.7 & 1.9 & 1.6 & 3.0 \\
\hline 150 & 94.0 & 79.5 & 11.6 & 2.1 & 1.8 & 2.0 & 3.0 \\
\hline
\end{tabular}

[a] Reaction conditions: $\mathrm{T}=120^{\circ} \mathrm{C}, \mathrm{PO}_{2}=4$ bar, stirring rate $=1,000 \mathrm{rpm}$, catalyst $=18 \mathrm{mg}$, benzyl alcohol $=2.5 \mathrm{~g}$

The effect of varying the oxygen partial pressure while keeping all other parameters constant is shown in Figure $7 \mathrm{~b}$ and Table 6 . The oxygen partial pressure profoundly affected the activity and product selectivity. High conversion of benzyl alcohol (>98\%) was achieved at 10 bar, compared to only $65.6 \%$ at 1 bar. The selectivity towards benzaldehyde was enhanced at higher oxygen partial pressures, reaching $86.7 \mathrm{~mol} \%$ at $10 \mathrm{bar}$. The highest yield of benzaldehyde (ca. $85.3 \mathrm{~mol} \%$ ) was achieved at 10 bar. Increasing the oxygen partial pressure appears to have a near linear effect on benzaldehyde selectivity and yield. Surprisingly, higher oxygen pressures did not lead to significant formation of benzoic acid, but contributed more to suppression of the formation of toluene. The solubility of $\mathrm{O}_{2}$ in benzyl alcohol increases with pressure, which leads to an increase in the oxygen available at the catalyst surface. More $\mathrm{O}_{2}$ availability enhances the reaction rate, and favours the oxidative dehydrogenation reaction pathway in the formation of benzaldehyde at the expense of the disproportionation pathway, which is responsible for toluene production.

The effect of varying the reaction temperature is given in Figure 7c and Table 7. The conversion and TOF increased considerably with temperature, while the selectivity towards benzaldehyde decreased. The selectivity towards toluene is enhanced markedly with temperature, increasing from less than $1 \mathrm{~mol} \%$ at $80^{\circ} \mathrm{C}$ to $23.6 \mathrm{~mol} \%$ at $140^{\circ} \mathrm{C}$. High reaction temperatures, therefore, enhance the rate of benzyl alcoho disproportionation. The yield of benzaldehyde increased with temperature up to $120^{\circ} \mathrm{C}$, and started to decline at $140^{\circ} \mathrm{C}$ as more toluene and heavy compounds are formed. Hence, it appears that $120^{\circ} \mathrm{C}$ is the optimum temperature for maximum yield of benzaldehyde over these catalysts.

Table 6. Benzyl alcohol conversion and product selectivity at different oxygen partial pressures for Au-Pd/Ti-NT ${ }^{\mathrm{SI}-\mathrm{R}}[\mathrm{a}]$

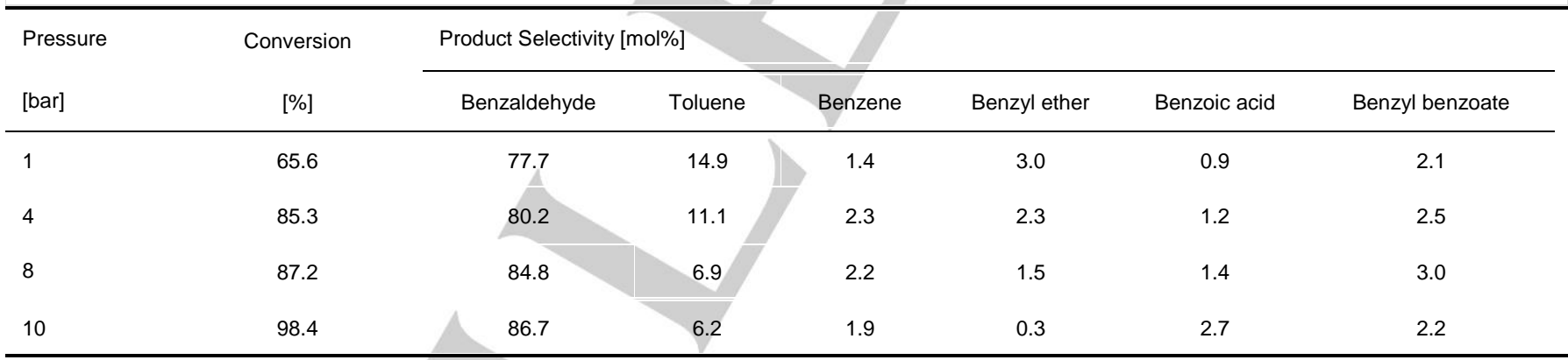

[a] Reaction conditions: $\mathrm{T}=120^{\circ} \mathrm{C}$, stirring rate $=1,000 \mathrm{rpm}$, reaction time $=1$ hour, catalyst $=18 \mathrm{mg}$, benzyl alcohol $=2.5 \mathrm{~g}$. 
Table 7. Benzyl alcohol conversion and product selectivity at different temperatures for Au-Pd/Ti-NT ${ }^{\mathrm{SI}-\mathrm{R}}$ [a]

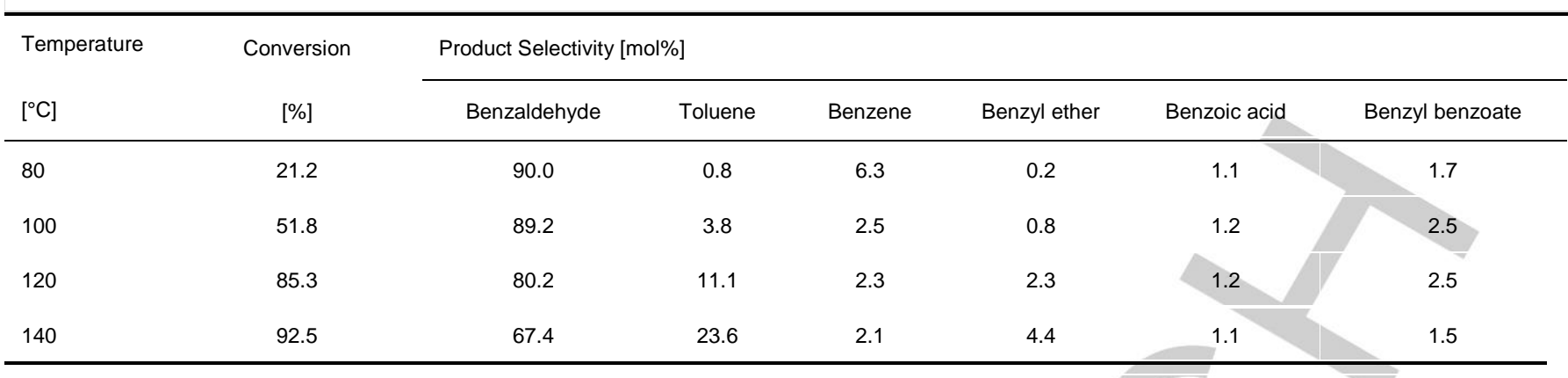

[a] Reaction conditions: $\mathrm{PO}_{2}=4$ bar, stirring rate=1,000 rpm, reaction time $=1$ hour, catalyst=18 $\mathrm{mg}$, benzyl alcohol $=2.5 \mathrm{~g}$

\section{Metal leaching, catalyst deactivation and re-use}

The stability and reusability were investigated using catalyst Au$\mathrm{Pd} / \mathrm{Ti}^{-N T^{S I}-\mathrm{R}}$. Leaching of active components into the reaction medium was investigated as follows. The oxidation reaction was carried out for 30 minutes over Au-Pd/Ti-NTSI-R at the normal reaction condition $\left(T=120^{\circ} \mathrm{C}, \mathrm{P}_{\mathrm{O} 2}=4\right.$ bar, stirring rate $=1,000$ rpm). The catalyst was subsequently removed and the liquid aliquot was returned to the reactor, and the reaction was run for an additional 60 minutes. Very small increase in the conversion was observed (Figure 8). This marginal increase in conversion is due to autoxidation of benzyl alcohol under the reaction conditions. Indeed, a similar conversion ( $4.4 \%$ ) was observed in blank runs (Table 4). Furthermore, no traces of Au or Pd were detected when the reaction liquid was analysed by ICP-AES.

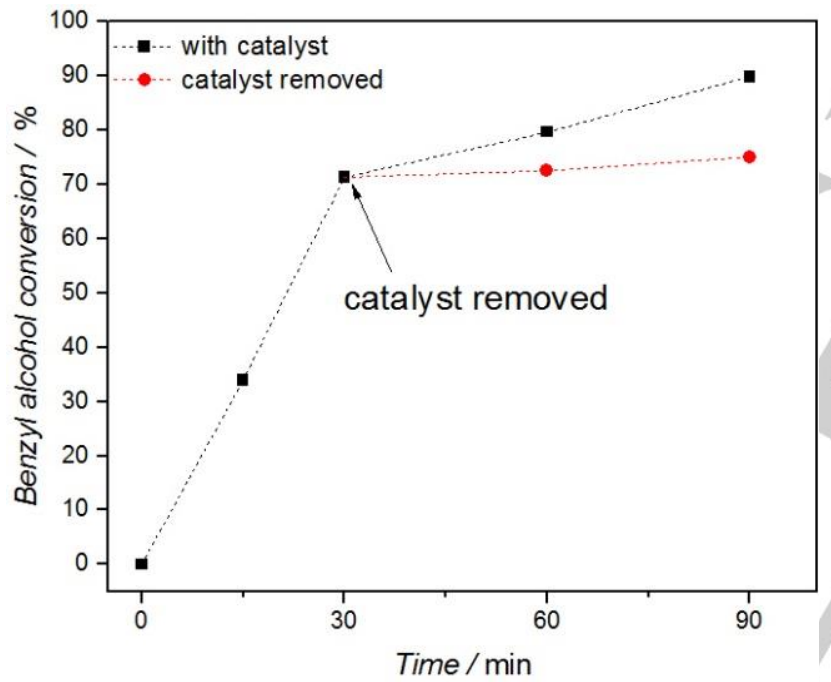

Figure 8. Catalyst leaching test for Au-Pd/Ti-NTSI-R

The catalytic performance of $\mathrm{Au}-\mathrm{Pd} / \mathrm{Ti}-\mathrm{NT} \mathrm{T}^{\mathrm{Sl}-\mathrm{R}}$ was investigated with repeated usage. After each catalytic test, Au$\mathrm{Pd} / \mathrm{Ti}_{\mathrm{N}} \mathrm{NT}^{\mathrm{SI}-\mathrm{R}}$ was recycled by washing the recovered catalyst several times with ethanol. A mild loss in activity and a slight drop in TOF and benzaldehyde yield was observed after usage: the TOF dropped by $12 \%$ after the first use, and $8 \%$ in the third use, Figure 9. Despite this, the Au-Pd/Ti-NT ${ }^{S I-R}$ catalyst appears to be more stable than similar $\mathrm{Au}-\mathrm{Pd}-\mathrm{PVA} / \mathrm{TiO} \mathrm{O}_{2}$ catalysts prepared by sol-immobilisation for which an activity drop of $\sim 30 \%$ was reported after the first use, and $\sim 60 \%$ after the second use ${ }^{[23]}$

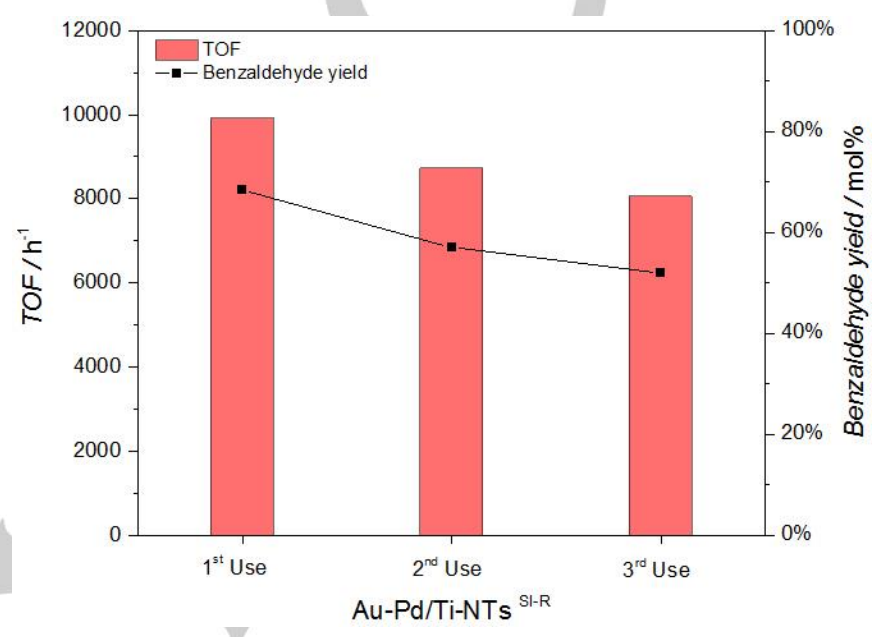

Figure 9. Benzaldehyde yield and TOF for recycled $\mathrm{Au}-\mathrm{Pd} / \mathrm{Ti}-\mathrm{NT} \mathrm{T}^{\mathrm{SI}-\mathrm{R}}$. Reaction conditions: $\mathrm{T}=120^{\circ} \mathrm{C}, \mathrm{P}_{\mathrm{O} 2}=4 \mathrm{bar}$, stirring rate $=1,000 \mathrm{rpm}$, reaction time $=1$ hour, catalyst $=18 \mathrm{mg}$, benzyl alcohol $=2.5 \mathrm{~g}$.

Table 9. Metal loading and weight loss for recycled Au-Pd/Ti-NTSI-R

\begin{tabular}{|c|c|c|c|c|}
\hline Catalyst & $\begin{array}{l}\mathrm{Pd} \\
\text { loading }^{\mathrm{aa}}\end{array}$ & $\begin{array}{c}\mathrm{Au} \\
\text { loading }^{[\mathrm{a}]}\end{array}$ & $\begin{array}{c}\mathrm{Pd} / \mathrm{Au} \\
\text { weight } \\
\text { ratio }\end{array}$ & $\begin{array}{l}\text { Weight } \\
\text { loss }^{[b]}\end{array}$ \\
\hline & [wt.\%] & [wt.\%] & & [wt.\%] \\
\hline $\begin{array}{l}\text { Au-Pd/Ti-NTSI-R } \\
\text { (fresh catalyst) }\end{array}$ & 0.77 & 0.70 & 0.91 & 4.09 \\
\hline $\begin{array}{l}\text { Au-Pd/Ti-NT }{ }^{\text {SI-R }} \\
\text { (after } 1^{\text {st }} \text { use) }\end{array}$ & 0.74 & 0.65 & 1.13 & 18.9 \\
\hline $\begin{array}{l}\text { Au-Pd/Ti-NTSI-R } \\
\text { (after } 2^{\text {nd }} \text { use) }\end{array}$ & 0.72 & 0.64 & 1.13 & 8.16 \\
\hline
\end{tabular}

[a] Weight percentage per gram of sample as obtained by ICP-AES analysis. [b] Weight loss calculated based on TGA results $\left(200-550^{\circ} \mathrm{C}\right)$.

Catalyst deactivation and activity loss can be due to one or more of several factors: leaching of active components from the support, sintering of metal particles, and poisoning of active sites. In the present case, no metal leaching into the reaction liquid was observed during the runs. However, a small amount of $\mathrm{Au}$ 
and Pd (with only a small change in the Au/Pd ratio) was lost during the catalyst washing cycles between each test, Table 9, which probably contributes to the observed drop in the catalytic activity with re-use.

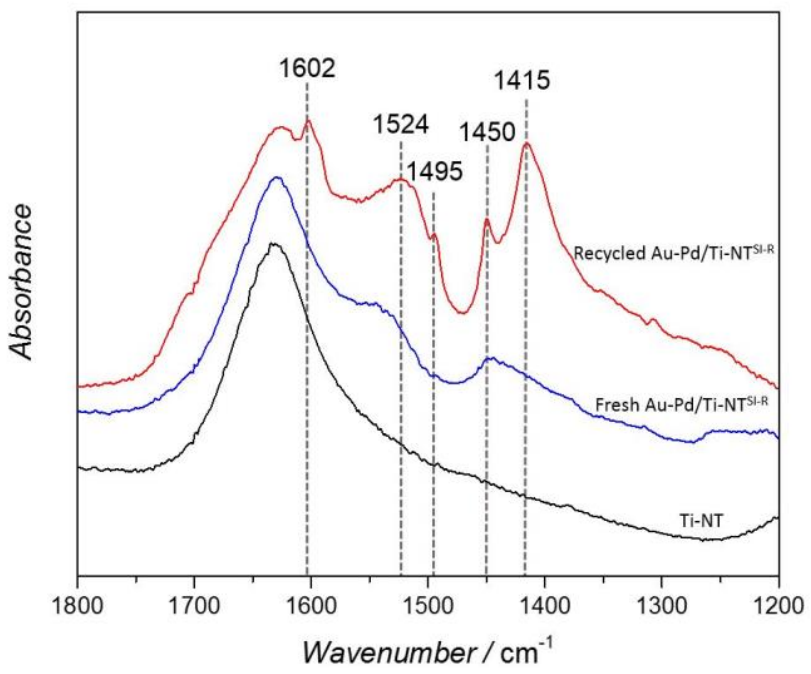

Figure 10. FT-IR spectra for as-synthesised Ti-NT, fresh and recycled Au$\mathrm{Pd} / \mathrm{Ti}-\mathrm{NT}{ }^{\mathrm{SI}-\mathrm{R}}$ catalysts.

As for sintering and metal particle growth, previous studies have shown that the particle size of PVA-derived Au-Pd NPs remains unchanged with repeated benzyl alcohol oxidation reaction cycles ${ }^{[23]}$. Therefore, blocking of the catalytic sites by adsorbed products (i.e. product inhibition) was investigated using thermogravimetric analysis (TGA) and FT-IR. The TGA of the used catalysts, albeit being washed and dried three times, exhibited a higher weight loss $\left(200-550{ }^{\circ} \mathrm{C}\right)$ than the fresh catalyst: 4 wt. \% for the fresh catalyst and $19 \%$ and $8 \%$ after the 1 st and 2nd use, respectively (Table 9). The weight loss observed in this temperature range $\left(200-550{ }^{\circ} \mathrm{C}\right)$ is due to the decomposition of carbon-based species (i.e. adsorbed products + residual PVA). To confirm the nature of the absorbed species, the fresh and the washed and recycled catalysts were analysed with FT-IR. In the washed and recycled catalyst, several new bands were observed, Figure 10. The new and strong bands at $1524 \mathrm{~cm}^{-1}\left(v_{\mathrm{a}} \mathrm{COO}^{-}\right), 1415$ ( $\left.v_{\mathrm{s}} \mathrm{COO}-\right)$ are characteristic of carboxylate functionality ${ }^{[40]}$. The bands appearing at 1602 and $1495 \mathrm{~cm}^{-1}$ are associated with the aromatic $v(\mathrm{C}=\mathrm{C})+\delta(\mathrm{C}-\mathrm{H})$ modes ${ }^{[41]}$. These results are in agreement with recent studies which showed that benzoic acid and benzoate species tend to be strongly adsorbed on the surface of Au-Pd-PVA/TiO ${ }_{2}^{[41]}$ even when heated to $280^{\circ} \mathrm{C}$, and that the addition of a small amount of benzoic acid at the beginning of the reaction led to a marked drop in the activity of $\mathrm{Au}-\mathrm{Pd}-\mathrm{PVA} / \mathrm{TiO}_{2}$ in the selective oxidation of benzyl alcohol[23]. Wang et al. ${ }^{[40]}$ carried out a detailed spectroscopic study on the interaction of benzoic acid with TiNTs found that benzoic acid can disperse spontaneously onto the surface of titanate nanotubes in a sub-monolayer state, and concluded that carboxylate species were formed by chemical reaction of the surface hydroxyl groups on Ti-NTs with carboxylic acid functionalities. These studies and the present findings reinforce the conclusion that the mild fall in activity observed with repeated usage of $\mathrm{Au}-\mathrm{Pd} / \mathrm{Ti}-\mathrm{NT}^{\mathrm{SI}-\mathrm{R}}$ is associated mainly with the seemingly irreversible adsorption of benzoic acid and benzyl benzoate by the catalyst.

\section{Conclusions}

In this work, a highly active Au-Pd catalyst for selective oxidation of benzyl alcohol has been produced on a titanate nanotube support, which was synthesised to have as low a sodium content as possible, by a sol-immobilisation method. The new catalyst was shown to be significantly more active, achieving higher TOFs, than similar $\mathrm{Au}-\mathrm{Pd} / \mathrm{TiO} \mathrm{O}_{2}$ catalysts reported in the literature and a catalyst prepared by conventional impregnation of standard P25 titania support. It was also shown to be more active in comparison with a Au-Pd catalyst prepared by the adsorption method reported previously. Through detailed characterisation of the catalyst structure, morphology and composition, the high catalytic activity of the Au-Pd/Ti-NTSI-R catalyst was attributed to the regular, small $\mathrm{Au}-\mathrm{Pd}$ particle size, the near complete alloying of $\mathrm{Au}$ and $\mathrm{Pd}$ in each individual NP, and the high dispersion of Au-Pd NPs on the external surfaces of Ti-NTs leading to good accessibility by the reactants to the active catalytic particles.

A study of catalyst deactivation and reuse showed that metal leaching during reaction was negligible, and that irreversible adsorption of the deep oxidation products benzioc acid and benzyl benzoate was the main cause of deactivation in agreement with previous work. Despite this, Au-Pd/Ti-NT ${ }^{\mathrm{Sl}-\mathrm{R}}$ catalyst suffered only a $19 \%$ loss in activity over three use cycles, which compares favourably in terms of stability with AuPd catalysts reported in the literature.

The catalytic performance of Au-Pd/Ti-NT ${ }^{S-R}$ in the selective oxidation of benzyl alcohol was dependent on the reaction conditions, and in particular the side reaction of disproportionation of benzyl alcohol to benzaldehyde and toluene was promoted at high temperatures and low oxygen partial pressures.

The catalyst described here can be expected to be active in several other selective oxidation reactions. In principle, the approach used here could be applied to synthesis catalysts with other precious metals supported on Ti-NTs.

\section{Experimental Section}

\section{Materials}

All metal precursors and chemical reagents were purchased from Sigma Aldrich and used as received: $\mathrm{NaOH}(99.99 \%$ trace metals basis), $\mathrm{H}_{2} \mathrm{SO}_{4}\left(\geq 97.5 \%\right.$ purity), $\mathrm{TiO}_{2}$ (Aeroxide ${ }^{\circledR} \mathrm{P} 25$ ), poly(vinyl alcohol) (PVA) (Mw 9,000-10,000, 80\% hydrolysed), $\mathrm{HAuCl}_{4} .3 \mathrm{H}_{2} \mathrm{O}\left(99.999 \%\right.$ purity), $\mathrm{PdCl}_{2}$ (5 wt. \% in 10 wt. \% $\mathrm{HCl}$ ), $\mathrm{NaBH}_{4}$ (Aldrich $\geq 98.0 \%$ ), Palladium(II) acetate $(\geq 99.9 \%$ purity) Benzyl alcohol (99.8\% purity). $\mathrm{O}_{2}(100 \%$ pure) for catalytic tests was supplied by BOC.

\section{Synthesis of titanate nanotubes (Ti-NTs)}

Titanate Nanotubes (Ti-NTs) were synthesised by the alkaline hydrothermal treatment method as reported by Kasuga et al. [19]. In a typical synthesis, $11 \mathrm{~g}$ of $\mathrm{TiO}_{2}$ (anatase nanopowder, $99.7 \%$ Sigma Aldrich) was added to $185 \mathrm{~mL}$ of $10 \mathrm{M} \mathrm{NaOH}$ in a $200 \mathrm{~mL}$ PTFE-liner and stirred for two hours. The PTFE-lined steel autoclave was then placed in an air-circulating oven at $140^{\circ} \mathrm{C}$ for 24 hours. The obtained slurry was then washed with DI water filtered and dried overnight at $120^{\circ} \mathrm{C}$. The dried powder was washed once with $0.1 \mathrm{M} \mathrm{H}_{2} \mathrm{SO}_{4}$ and several times with distilled water until $\mathrm{pH} 7$ is reached. The obtained powder was subsequently filtered dried. These Ti-NTs contained some residual $\mathrm{Na}$ and was denoted to as Ti-NT-1. A portion of Ti-NT-1 was acid treated once more, and denoted to by Ti-NT-2. 


\section{Catalysts prepared by sol-immobilisation (Au-Pd/Ti-NT ${ }^{\mathrm{S}}$ )}

Catalysts were prepared in manner similar to the solimmobilisation procedure previously reported ${ }^{[21]}$. First, the Ti-NT2 were acidified to a pH below the point of zero charge (PZC). The PZC of Ti-NTs was measured and found to be $\sim 5.2$. Typically, $1.0 \mathrm{~g}$ of the support was added to $75 \mathrm{~mL}$ of water and a $1 \mathrm{M}$ solution of $\mathrm{H}_{2} \mathrm{SO}_{4}$ was added drop-wise to the slurry until the $\mathrm{pH}$ dropped to $\sim 1.5$. After 2 hours of vigorous stirring, the slurry was filtered and the acidified support was collected. The metal colloid or sol was prepared by adding calculated amounts of the gold precursor $\left(\mathrm{HAuCl}_{4} \cdot 3 \mathrm{H}_{2} \mathrm{O}\right)$ and palladium precursor $\left(\mathrm{PdCl}_{2}, 5 \mathrm{wt} . \%\right.$ in $\left.\mathrm{HCl}\right)$ to $100 \mathrm{~mL}$ of $\mathrm{DI}$ water at $5^{\circ} \mathrm{C}$ while stirring vigorously at $1,500 \mathrm{rpm}$. Subsequently, $2,400 \mathrm{mg}$ of $1.0 \mathrm{wt} . \%$ PVA solution was added to the solution and stirred for 15 minutes. PVA was used as a stabiliser herein and the weight ratio of $\mathrm{PVA} /(\mathrm{Au}+\mathrm{Pd})$ was kept at 1.2. The metal precursors were reduced in-situ by the addition of an excess amount of $\mathrm{NaBH}_{4}$ such that the molar ratio of $\mathrm{NaBH}_{4}:(\mathrm{Au}+\mathrm{Pd})$ was $5: 1$. More specifically, $7.5 \mathrm{~mL}$ of $0.1 \mathrm{M} \mathrm{NaBH}_{4}$ was added to the solution. The solution turned brown immediately upon the addition of $\mathrm{NaBH}_{4}$, which confirmed the formation of the sol. The sol was left stirring for 1 hour before the acidified Ti-NTs were added to form a slurry. The $\mathrm{pH}$ of the slurry was maintained at $\sim 3$ during the immobilisation of the Au-Pd sol on the Ti-NTs. The slurry was left stirring overnight before it was filtered and washed with DI water several times until the $\mathrm{pH}$ of the mother liquor reached $\sim 7.0$. The obtained catalyst was finally dried overnight at $120^{\circ} \mathrm{C}$. A portion of the dried catalyst was refluxed in hot water $\left(90^{\circ} \mathrm{C}\right)$ for 60 minutes, filtered and dried overnight at $120{ }^{\circ} \mathrm{C}$. This treated catalyst portion was denoted to as $\mathrm{Au}-$ $\mathrm{Pd} / \mathrm{Ti}-\mathrm{NT} \mathrm{TS}^{\mathrm{S}-\mathrm{R}}$

\section{Catalysts prepared by adsorption (Au-Pd/Ti-NTADS)}

The required amounts of $\left(\mathrm{HAuCl}_{4} .3 \mathrm{H}_{2} \mathrm{O}\right)$ and $\left(\mathrm{PdCl}_{2}, 5\right.$ wt.\% in $\mathrm{HCl}$ ) corresponding to the desired loadings were added to 100 $\mathrm{mL}$ of DI water at $80^{\circ} \mathrm{C}$. Under vigorous stirring conditions, $1.0 \mathrm{~g}$ of the support (Ti-NT-1) was added to the solution. After 18 hours, the solution was filtered and dried overnight at $120^{\circ} \mathrm{C}$. The catalyst was then reduced for 2 hours at $200^{\circ} \mathrm{C}$ in a tube furnace under a continuous flow of diluted hydrogen $\left(5 \mathrm{vol} . \% \mathrm{H}_{2}\right.$ (Ar). The furnace ramp rate was set to $5^{\circ} \mathrm{C} / \mathrm{min}$, and gas flow rate was fixed at $\sim 50 \mathrm{~mL} / \mathrm{min}$.

\section{Catalysts prepared by dry Impregnation (Au-Pd/TiO $\left.{ }_{2}{ }^{\mathrm{Dl}}\right)$}

The requisite amounts $\left(\mathrm{HAuCl}_{4} \cdot 3 \mathrm{H}_{2} \mathrm{O}\right)$ and $\left(\mathrm{PdCl}_{2}, 5\right.$ wt. \% in $\mathrm{HCl})$ were dissolved in a predetermined volume of $\mathrm{DI}$ water to give a surface loading of $\sim 200,000 \mathrm{~m}^{2} / \mathrm{L}$. The precursor solution was added drop-wise to the support $\left(\mathrm{TiO}_{2}\right.$, Aeroxide $\left.{ }^{\circledR} \mathrm{P} 25\right)$ to form a fine paste. The paste was dried overnight at $120^{\circ} \mathrm{C}$, and then reduced under the same conditions described in the previous section.

\section{Reaction procedure}

Benzyl alcohol oxidation was carried out in batch mode using 25 $\mathrm{mL}$ glass-lined minclaves (Buchiglas, Switerland). In a typical run, benzyl alcohol $(2.50 \mathrm{~g})$ and the requisite amount of catalyst were charged to the reactor before it was purged five times with $\mathrm{O}_{2}$. The reactor was subsequently pressurised with $\mathrm{O}_{2}$ to the required pressure at room temperature. The reactor was heated in an oil bath set at the desired temperature and stirred at 1,000 rpm. An oxygen reservoir was connected to the reactor to ensure that any oxygen consumed by the reaction was replenished. The reactor pressure was controlled using a forward-pressure regulator and a series of check-valves. At the end of each run, the reactor was cooled down to room temperature and vented. The reaction mixture was dissolved in
$20 \mathrm{~mL}$ of acetonitrile and then centrifuged at 5,000 rpm for 15 minutes to separate out the catalyst. A sample from the supernatant $(600 \mu \mathrm{L})$ was taken out and added to $100 \mu \mathrm{L}$ of $\mathrm{n}$ butanol (internal standard) prior to product analysis. Analysis of the reaction products was carried out using a GC (Shimadzu GC-2014) fitted with a Flame lonization Detector (FID), and a wax column (Agilent CP WAX $52 \mathrm{CB}$ UltiMetal, $\mathrm{L}=25 \mathrm{~m}, \mathrm{ID}=$ $0.53 \mathrm{~mm}$, film thinness $=2.0 \mu \mathrm{m})$. Carbon balance was $96 \pm 3 \%$. Benzyl alcohol (BA) conversion $\left(X_{B A}\right)$, product yield $\left(Y_{i}\right)$, and selectivity $\left(S_{i}\right)$ were calculated using the following equations:

$$
\begin{gathered}
Y_{i}(w t . \%)=\frac{w_{i}}{w_{B A}^{\circ}} \times 100 \% \\
X_{B A}(\%)=\sum_{i=1}^{n} Y_{i}(w t . \%) \\
S_{i}(m o l \%)=\frac{n_{i}}{\sum_{i=1}^{n} n_{i}} \times 100 \% \\
Y_{B A L}(m o l \%)=\frac{n_{B A L}}{n_{B A}^{\circ}} \times 100 \%
\end{gathered}
$$

Where: $w_{B A}$ is the initial weight of benzyl alcohol, $w_{i}$ is the final weight of product $i, n_{B A}$ is the initial number of moles of benzyl alcohol, and $n_{i}$ is the final number of moles of product $i, n_{B A L}$ is the final amount of benzaldehyde. Conversion and selectivity values reported represent the average of three experiments. The \%standard deviation for the conversion was ca. $2.5 \%$ for the conversion and less than $1 \%$ for the selectivities.

\section{Metal leaching and catalyst re-use}

In order to quantify any leaching of active components occurring during the course of the reaction, the oxidation of benzyl alcohol was carried out for 30 minutes in the presence of Au-Pd/Ti-NTSI$\mathrm{R}$, and then terminated. The reaction slurry was subsequently centrifuged to separate out the catalyst, and the clean supernatant was filtered and returned to the reactor. After one hour, the reaction was terminated and the liquid was analysed with GC. In order to examine catalyst reusability, the used catalysts were washed with an excess amount of ethanol and centrifuged. The supernatant was removed, and the washing procedure was repeated three times. Next, the catalyst was dried overnight at $80{ }^{\circ} \mathrm{C}$. The catalytic activity of the recycled catalysts was tested under the same reaction conditions used for the fresh catalyst.

\section{Catalyst characterisation}

Catalysts were analysed by PANalytical X'Pert Pro MultiPurpose Diffractometer using Cu-Ka radiation. The analysis was performed over a scan angle of $5-70^{\circ} 2 \Theta$, and a step size of $0.0167 \%$ s. Nitrogen adsorption-desorption measurements were carried out at $-196^{\circ} \mathrm{C}$ using a Micromeritics TriStar II. Prior to carrying out any measurements, all samples were degased at $130^{\circ} \mathrm{C}$ for 12 hours. Brunauer-Emmett-Teller (BET) and BarrettJoyner-Halenda $(\mathrm{BJH})$ were used to measure the specific surface area $\left(\mathrm{S}_{\mathrm{BET}}\right)$, pore volume and pore diameter.

The final $\mathrm{Au}$ and $\mathrm{Pd}$ loadings were determined by inductively coupled plasma atomic emission spectroscopy (ICP-AES, PE Optima 2000 DV). Typically, $15 \mathrm{mg}$ of catalyst was dissolved in $15 \mathrm{~mL}$ of aqua regia, sonicated for 2 hours, and left overnight in order to completely dissolve any remaining solids. The samples were diluted with $20 \mathrm{~mL}$ of $\mathrm{DI}$ water before analysis. The 
instrument was calibrated with authenticated standards (Sigma Aldrich) containing predetermined amounts of each metal. The average particle size and distribution of the metal NPs were determined from high resolution transmission electron microscopy (HRTEM) images. Scanning transmission electron microscopy (STEM) and HRTEM images were collected using a JEOL JEM-2100F microscope operating at $200 \mathrm{kV}$.. Samples were dispersed in ethanol and sonicated for 30 minutes before they were placed on copper grids with a holey carbon film (300 mesh size). The particle size distribution and average particle size were determined by analysing 100 randomly selected nanoparticles in each catalyst sample. Energy Dispersive X-Ray Analysis (EDX) provided elemental analysis and was carried out using a X-MaxN $80 \mathrm{~T}$ Silicon Drift Detector from Oxford Instruments. X-ray photoelectron spectroscopy (XPS) measurements were recorded using a Thermo K-Alpha Spectrometer equipped with Al Ka source gun. Samples were mounted on double-sided adhesive tape, and the spectra were collected using an X-ray spot size of $400 \mu \mathrm{m}$ and a pass energy of $20 \mathrm{eV}$ with $0.1 \mathrm{eV}$ increments. The binding energies (BE) were referenced to the $\mathrm{C}(1 \mathrm{~s})$ peak of adventitious carbon at $284.8 \mathrm{eV}$. Data analysis and peak fitting was performed using Avantage software from Thermo Scientific. Thermogravimetric analysis (TGA) was carried under flowing air (60 mL/min) using TGA Q500 (TA Instruments). Samples were heated at a rate of $10^{\circ} \mathrm{C} / \mathrm{min}$ to a final temperature of $550^{\circ} \mathrm{C}$. The point of zero charge for the as-synthesised Ti-NTs was determined by measuring the zeta potential of Ti-NTs as a function of $\mathrm{pH}$ using Brookhaven ZetaPALS Potential Analyzer. Ti-NTs were dispersed in solutions of $\mathrm{HNO}_{3}$ and $\mathrm{KOH}$ at varying $\mathrm{pH}$ values ranging from 2 to 11 . FT-IR measurements were performed using PerkinEImer Spectrum 100

\section{Acknowledgements}

Motaz Khawaji gratefully acknowledges the financial support of Saudi Aramco. This work was funded in part by EPSRC $(E P / K 014749 / 1)$. We are grateful to Dr. Ecaterina Ware for her assistance with TEM.

Keywords: Gold-palladium • titanate nanotubes $\bullet$ selective oxidation • sol-immobilisation $\bullet$ benzyl alcohol

[1] M. Haruta, T. Kobayashi, H. Sano, N. Yamada, Chemistry Letter 1987, 16, 405-408.

G. J. Hutchings, Journal of Catalysis 1985, 96, 292-295.

[3] T. Hayashi, K. Tanaka, M. Haruta, Journal of Catalysis 1998, 178, 566-575.

[4] L. Prati, M. Rossi, Journal of Catalysis 1998, 176, 552-560

[5] R. Zhao, D. Ji, G. Lv, G. Qian, L. Yan, X. Wang, J. Suo, Chem Commun (Camb) 2004, 904-905

[6] P. Landon, P. J. Collier, A. J. Papworth, C. J. Kiely, G. J. Hutchings, Chemical Communications 2002, 2058-2059.

[7] A. Villa, D. Wang, D. S. Su, L. Prati, Catal. Sci. Technol. 2015, 5, 55-68.

[8] D. I. Enache, J. K. Edwards, P. Landon, B. Solsona-Espriu, A. F Carley, A. A. Herzing, M. Watanabe, C. J. Kiely, D. W. Knight, G. J. Hutchings, Science 2006, 311, 362-365.

[9] J. H. Carter, S. Althahban, E. Nowicka, S. J. Freakley, D. J. Morgan, P. M. Shah, S. Golunski, C. J. Kiely, G. J. Hutchings, ACS Catalysis 2016, 6, 6623-6633.

[10] D. I. Enache, D. Barker, J. K. Edwards, S. H. Taylor, D. W. Knight, A. F. Carley, G. J. Hutchings, Catalysis Today 2007, 122, 407-411. R. Mueller, H. K. Kammler, K. Wegner, S. E. Pratsinis Langmuir 2003, 19, 160-165.
D. V. Bavykin, F. C. Walsh, Titanate and Titania Nanotubes Synthesis, 2009.

[13] A. Villa, D. Wang, G. M. Veith, F. Vindigni, L. Prati, Catalysis Science \& Technology 2013, 3, 3036-3041.

[14] D. V. Bavykin, A. A. Lapkin, P. K. Plucinski, L. Torrente-Murciano, J. M. Friedrich, F. C. Walsh, Topics in Catalysis 2006, 39, 151-160. Á. Kukovecz, K. Kordás, J. Kiss, Z. Kónya, Surface Science

[15] A. Kukovecz, K. Kordás, J. Kiss, Z. Kónya, Surface Science
Reports 2016, 71, 473-546.

[16] L. Torrente-Murciano, Q. He, G. J. Hutchings, C. J. Kiely, D. Chadwick, ChemCatChem 2014, 6, 2531-2534.

[17] L. Torrente-Murciano, T. Villager, D. Chadwick, ChemCatChem 2015, 7, 925-927.

[18] D. Nepak, S. Darbha, Catalysis Communications 2015, 58, 149 153.

[19] T. Kasuga, M. Hiramatsu, A. Hoson, T. Sekino, K. Niihara Langmuir 1998, 14, 3160-3163.

[20] F. Porta, L. Prati, M. Rossi, S. Coluccia, G. Martra, Catalysis Today 2000, 61, 165-172.

[21] N. Dimitratos, J. A. Lopez-Sanchez, D. Morgan, A. F. Carley, R. Tiruvalam, C. J. Kiely, D. Bethell, G. J. Hutchings, Phys Chem Chem Phys 2009, 11, 5142-5153.

[22] N. Dimitratos, F. Porta, L. Prati, Applied Catalysis A: General 2005, 291, 210-214.

[23] J. Wang, S. A. Kondrat, Y. Wang, G. L. Brett, C. Giles, J. K Bartley, L. Lu, Q. Liu, C. J. Kiely, G. J. Hutchings, ACS Catalysis 2015, 5, 3575-3587.

[24] S. K. Pradhan, Y. Mao, S. S. Wong, P. Chupas, V. Petkov Chemistry of Materials 2007, 19, 6180-6186.

[25] T. Gao, H. Fjellvåg, P. Norby, Inorganic Chemistry 2009, 48, 1423 1432.

[26] E. Morgado, M. A. S. de Abreu, G. T. Moure, B. A. Marinkovic, P. M. Jardim, A. S. Araujo, Chemistry of Materials 2007, 19, 665-676. L. Prati, A. Villa, Acc Chem Res 2014, 47, 855-863.

[28] M.-C. Daniel, D. Astruc, Chemical Reviews 2004, 104, 293-346.

[29] J. A. Lopez-Sanchez, N. Dimitratos, C. Hammond, G. L. Brett, L. Kesavan, S. White, P. Miedziak, R. Tiruvalam, R. L. Jenkins, A. F. Carley, D. Knight, C. J. Kiely, G. J. Hutchings, Nat Chem 2011, 3, 551-556.

[30] B. Pawelec, A. M. Venezia, V. La Parola, E. Cano-Serrano, J. M. Campos-Martin, J. L. G. Fierro, Applied Surface Science 2005 , 242, 380-391

[31] I. Gandarias, P. J. Miedziak, E. Nowicka, M. Douthwaite, D. J. Morgan, G. J. Hutchings, S. H. Taylor, ChemSusChem 2015, 8 473-480.

[32] C. M. Olmos, L. E. Chinchilla, E. G. Rodrigues, J. J. Delgado, A. B. Hungría, G. Blanco, M. F. R. Pereira, J. J. M. Órfão, J. J. Calvino, X. Chen, Applied Catalysis B: Environmental 2016, 197, 222-235. aA. M. Venezia, L. F. Liotta, G. Pantaleo, V. La Parola, G. Deganello, A. Beck, Z. Koppány, K. Frey, D. Horváth, L. Guczi, Applied Catalysis A: General 2003, 251, 359-368; bP. A. P. Nascente, S. G. C. de Castro, R. Landers, G. G. Kleiman, Physical Review B 1991, 43, 4659-4666.

[34] C. M. Olmos, L. E. Chinchilla, J. J. Delgado, A. B. Hungría, G. Blanco, J. J. Calvino, X. Chen, Catalysis Letters 2016, 146, 144156.

[35] S. Meenakshisundaram, E. Nowicka, P. J. Miedziak, G. L. Brett, R. L. Jenkins, N. Dimitratos, S. H. Taylor, D. W. Knight, D. Bethell, G. J. Hutchings, Faraday Discussions 2010, 145, 341-356.

[36] C. H. Bartholomew, R. J. Farrauto, Fundamentals of Industrial Catalytic Processes, John Wiley \& Sons, 2011.

[37] aE. Cao, M. Sankar, S. Firth, K. F. Lam, D. Bethell, D. K. Knight, G. J. Hutchings, P. F. McMillan, A. Gavriilidis, Chemical Engineering Journal 2011, 167, 734-743; bS. S. Hladyi, M. K. Starchevsky, Y. A. Pazdersky, M. N. Vargaftik, I. I. Moiseev, Mendeleev Communications 2002, 12, 45-46.

[38] aG. Kovtun, T. Kameneva, S. Hladyi, M. Starchevsky, Y. Pazdersky, I. Stolarov, M. Vargaftik, I. Moiseev, Advanced Synthesis \& Catalysis 2002, 344, 957-964; bE. H. Cao, M. Sankar E. Nowicka, Q. He, M. Morad, P. J. Miedziak, S. H. Taylor, D. W. Knight, D. Bethell, C. J. Kiely, A. Gavriilidis, G. J. Hutchings, Catalysis Today 2013, 203, 146-152.

[39] D. M. Meier, A. Urakawa, A. Baiker, The Journal of Physical Chemistry C 2009, 113, 21849-21855.

[40] W. Wang, J. Zhang, H. Huang, Z. Wu, Z. Zhang, Applied Surface Science 2007, 253, 5393-5399.

[41] E. Nowicka, J. P. Hofmann, S. F. Parker, M. Sankar, G. M. Lari, S. A. Kondrat, D. W. Knight, D. Bethell, B. M. Weckhuysen, G. J. Hutchings, Physical Chemistry Chemical Physics 2013, 15, 12147 12155. 


\section{FULL PAPER}

A highly active Au-Pd/Ti-NT catalyst has been produced using colloidal synthesis and immobilisation on essentially sodium-free titanate nanotubes (Ti-NT). The new catalyst has markedly superior catalytic activity (TOF $=>19,000 \mathrm{hr}^{1}$ ) for the selective oxidation of benzyl alcohol compared to similar catalysts reported in literature, and to Au-Pd catalysts supported on TiNTs prepared by adsorption, as well as conventional $\mathrm{Au}-\mathrm{Pd} / \mathrm{TiO}_{2}$ prepared by impregnation.

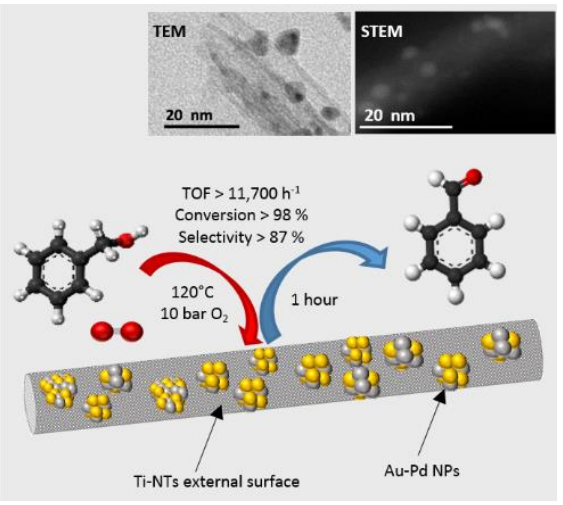

Motaz Khawaji, Prof. David Chadwick*

Page No.12 - Page No.12

Au-Pd Bimetallic Nanoparticles Immobilised on Titanate Nanotubes: A Highly Active Catalyst for Selective Oxidation 